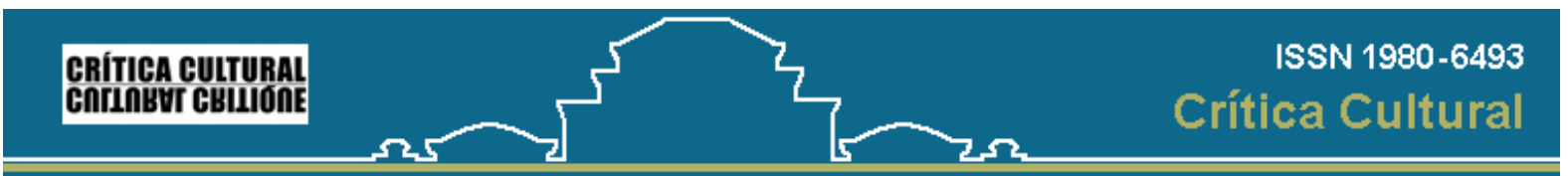

Crítica Cultural, volume 3, número 1, jan.jjun. 2008

\title{
SENSIBILIDADE INTELIGENTE, O “SI” DA CRITICA CLARICEANA
}

Simone Curi ${ }^{*}$

Resumo: 0 artigo, ao estabelecer um percurso para pensar uma crítica clariceana, recorre à produção jornalística realizada pela escritora. É, pois, através do que se convencionou chamar de 'baixa' produção, que se deixa ler uma crítica possível, desde uma hegemonia existente nos meios de comunicação, e não obstante, excede para outro nível de observação. Se a prática alternativa implica já deslocamento, e por isso mesmo, crítica, por outra, duplamente crítica, pois que na imprensa as fronteiras são abolidas, literatura, entretenimento, diário, postulações teóricas para o pensamento se fundem. Com o qual se entende a sedução do crítico menor, operando com a sensibilidade inteligente, termo que remete à intuição bergsoniana, detido nas mínimas manifestações da vida, chama para o inaudito. Singularidade da escritura-crítica que invade o jornal, e faz o leitor se deparar com pegadas que redimensionam a biblioteca de Clarice Lispector, mas fundamentalmente, às legítimas abordagens críticas, ao produzir um saber, amplia, de modo geral, o debate sobre a função crítica.

Palavras-chave: crítica, filosofia, Clarice Lispector, autobiografia.

\section{Sensibilidade inteligente, o "si" da crítica clariceana}

Toda poesia exprime estados de alma. Mas entre estes estados, alguns nascem sobretudo do contato do homem com os seus semelhantes. São os sentimentos mais intensos e também mais violentos $[1]$. E tantas vezes não consegui o encontro máximo de um ser consigo mesmo, quando com espanto dizemos "Ah!" às vezes esse encontro consigo mesmo se consegue através do encontro de um ser com outro $\underline{\text { [2] }}$.

1.

Desconstruir para revelar o 'em si', para aceder a possíveis realidades, procura que não pode vingar se negligencia o essencial de toda experiência, sua composição. Isso não quer dizer aprisionamento ao caráter genealógico, ainda que busque estabelecer alianças entre determinado circuito de pensamento. Assim, se para Clarice Lispector o ponto máximo que pode alcançar a escritura é quando se dá em consciência, numa coincidência, é também onde o ser se dá a si mesmo. A escritura filosofa, preexistindo nesse pensamento algo que tange à intuição bergsoniana. Virtualidades teóricas vão se inscrevendo no processo mesmo de leitura. Mas é a partir de uma entrevista jornalística que, aqui, uma linha começa a se desdobrar e atualizar a crítica clariceana.

Esse encontro, com Maria Martins [3] , permite também entrever a intimidade entre partícipes de uma roda privilegiada, a intelligentsia brasileira. Representada pela artista plástica, Maria Martins que, casada com o embaixador Carlos Martins, tomou parte do movimento surrealista e integrou a primeira Bienal de Artes de São Paulo. E Clarice Lispector, escritora, casada com o diplomata Maury Gurgel Valente, cuja obra, assinada em nome próprio, abala os cânones das letras nacionais, uma vez desconsiderados os seus limites. É, pois, na rota diplomática que uma comunidade se evidencia, entre bem-pensantes e burocratas, e junto dela artes cultivadas no contágio das muitas culturas percorridas.

Clarice, tocada pelas lembranças, pede a Maria que fale sobre sua atuação no meio diplomático, e recebe de volta: "Clarice, qual é a sua experiência de vida diplomática, você que é uma mulher inteligente?" (LISPECTOR: 1992b, p. 82)

$\mathrm{Na}$ inversão da hierarquia da entrevista, imediatamente corrige: "Não sou inteligente, sou sensível, Maria. E respondendo à sua pergunta: eu me refugiei em escrever". Apelando ao mesmo recurso anterior, Maria, à pergunta como preservara sua espontaneidade: "Respondo como você: porque me refugiei na arte" (LISPECTOR: 1992b, p. 82). A amizade, as artes, zonas que avizinham as duas individualidades, no entanto cada uma singular, ao apresentarem mundos que se configuram num além-representação. Nessa pequena abertura, ao se entrar no mundano das relações, as diplomáticas e também as de imprensa, uma espécie de proposta política se insinua: estar dentro e, ao mesmo tempo, à margem.

Desvio que significa certo despojamento dos artefatos (que constituem a existência), a fim de acessar o factum, a ficção [4] Como narra a lenda, no abandono da vida social, Clarice Lispector some, vira escritura: "Converteu-se na sua própria ficção" $\underline{\text { [5] }}$ (FRANCIS: 1977). Ficção concebida no distanciamento de um modelo intelectual, atravessando os dois níveis, vai em direção onde se dá a própria articulação, como estabelece em "Sensibilidade Inteligente"

Ser intelectual é usar sobretudo a inteligência, o que eu não faço: uso é a intuição, o instinto (...) Literata também não sou (...) sou uma pessoa que pretendeu pôr em palavras um mundo ininteligível e um mundo impalpável (...) cujo coração bate de alegria levíssima quando consegue em uma frase dizer alguma coisa sobre a vida humana ou animal (LISPECTOR: 1992ab, p. 152).

O estado de pensamento intuitivo se distende num pensar-ser: mesmo no mais prosaico (o jornal, o biográfico) é vislumbre do acontecimento, o ritmo perceptual (daquele que lê e é lido) afetando no que difere e, no entanto, revela-se tão próximo. Assim, passa-se de um nível a outro: uma inteligência enuncia um mundo impalpável. Mas o objeto de experimentação, que se manifesta no tempo-espaço, conforma-se segundo leis de entendimento. "Nós que escrevemos temos que pensar e intuir. Nós os que escrevemos temos na palavra humana, escrita ou falada, grande mistério que não quero desvendar com meu raciocínio que é frio". (LISPECTOR: 1980, p. 100)

Essa escritura traz em resumo a trajetória de Lóri: ao passar da incapacidade de entender a vida para o gozo do sentir-se viva, a vida em plenitude na escrita do Livro dos prazeres. Entender ou não, contingência que leva o 'fato' a ser essencialmente diferente do que é, de como se mostra. Se o fato determina o modo de estar no mundo, não determina o ser, porque é impossível apreender a facticidade em sua nudez bruta, pois tudo que se faz está 'assumido' e 'livremente construído' (SARTRE: 1997, p. 133); à afirmação de caráter existencialista, uma outra, distinta, que reconhece uma realidade em desnudamento:

(...) quer seja pintura, escultura, poesia ou música, a arte não tem outro objeto senão o de afastar os símbolos praticamente úteis, as generalizações convencionalmente e socialmente aceitas, tudo aquilo que enfim, que nos mascara a realidade em si (...) Que realidade é esta? (BERGSON: 1993, p. 111)

Talvez, a realidade do bobo - quer dizer, daquele que exacerba em compreensão, desvelando-lhe o em si. Além de qualquer intenção, mas em atenção à vida, é consciência de sua riqueza pródiga. 0 bobo, indecente imagem do ser sendo: exponibilidade, mais ainda, quando se torna mudez absoluta: "O bobo é capaz de ficar sentado quase sem se mexer por duas horas. Se perguntado por que não faz alguma coisa, responde: "Estou fazendo. Estou pensando". (LISPECTOR: 1992aa, p. 332)

Se, de um lado, a escritura prática, jornalística, transforma em informação o conjunto de acontecimentos inscritos no presente, aproximando-se da imagem de Fátua - mulher que se presta ao jogo cortês, entretendo pessoas que lhe dão de comer $\frac{[6]}{\text {. Existe, contudo, o }}$ seu outro, parte irmanada às Parcas, divindades romanas do destino, identificadas às Moiras dos gregos. Dotadas dos mesmos atributos, as três irmãs determinam o nascimento, casamento e morte das criaturas humanas. Tria fata conta sua história, trabalha o material da vida, 0 tempo. Fátua, solitária, apegada ao presente simples, ao trabalho alienado, quando, fraternalmente, se conjuga ao passado e ao futuro assume 
caráter pouco divertido. Advertindo sobre o inexorável do destino que implica seu tipo de narrativa.

Mas é do presente mesmo que se ilumina uma lembrança: visibilidade do sensível somente aos olhos do absurdo pensador privado

[7]. Ele apresenta, inocente de eternidade, a duração de um acontecido - a vida mesma (plena de amor fati - o mesmo do cordeiro para com seu lobo: "O tempo corre, o tempo é curto: preciso me apressar, mas ao mesmo tempo viver como se esta minha vida fosse eterna") (LISPECTOR: 1992ac, p. 100).

Ele, o idiota atual, irrompe o formal do pensamento, não conforma uma identidade desenhada de fora, reconhece em tudo reapresentação. Se a língua não traduz o real, só cria sentido (distintos falantes, distintos reais, formas diferentes de elaborar 0 mesmo), 0 momento intuitivo remete à intensidade do real, desorganizando as cronologias e sucessões instituídas. Mas depois do entrevisto, dali do rebordo, o que vem? A lucidez depois do espetáculo, por meio de uma memória ainda de ressaca, é que vai por fim narrar. Necessária memória imediata ao espírito, preenchendo a antiga separação: pela afetividade, com lembranças (relacionando os instantes e intercalando o futuro no passado no presente), contração da matéria restituindo a qualidade do corpo, outorgando-Ihe uma duração no tempo.

A grande força, ou idiotia, desse tipo de escritura é a potência do não, sonegar tributos à tribo, enquanto demonstra o fato como acontecimento póstumo (a história), condicionando a impressão à confirmação. Ao encerrar aquela entrevista, a Maria Martins, repentinamente, é permitido recontar - se pudesse - a história:

- Se você tivesse que recomeçar sua vida do início, que destino escolheria, se é que se escolhe destino?

Eu seria uma artista como sou, livre e libertada.

Maria, a vida é difícil. Mas vale a pena viver?

Vale, Clarice, porque a morte, afinal, é a última coisa de onde a gente não pode voltar. Apesar de tudo, acho

a vida uma beleza (LISPECTOR: 1992b, p. 84).

Já a resposta da artista plástica é pura afirmação ao fato da vida, da maior liberdade. Sem contradição, pois apesar da aparência (da morte não se volta), a intuição lhe com-prova um retorno, por isso reconta o mesmo: ser como se é. Da parte da entrevistadora: depois de qualificar a vida como difícil, justapõe-Ihe uma partícula (adversativa) neutralizadora do efeito anterior. Esse 'mas' implica uma vontade que comunga com a da entrevistada que, por sua vez, descomplica: 'apesar' de tudo, a vida é beleza. Valorizar a aparência é afirmar a força. Afirmação é liberdade de artista [8].

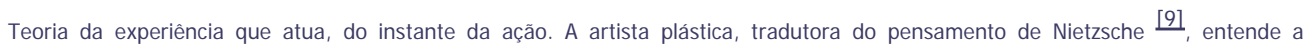
liberdade da vontade como liberdade de pensamento, baseada nas percepções adquiridas e ampliadas até os confins do ilimitado. Outra coisa distinta é o operar da vontade, não raras vezes, imposta de maneira fatalista. Compreende o filósofo:

Que são a força interior e a autodeterminação para o atuar e as manifestações exteriores - sua alavanca evolutiva - senão vontade livre e fatum?

Na vontade livre se cifra para o indivíduo o princípio da singularização, da separação com respeito do todo, do ilimitado; o fatum, contudo, põe outra vez o homem em estreita relação orgânica com a evolução geral e 0 obriga, enquanto que esta busca dominá-lo, a colocar em marcha forças reativas; uma vontade absoluta e livre, carente de fatum, faria do homem um deus; o princípio fatalista, ao contrário, um autômata (NIETZSCHE: 1997, p. 112).

Num fragmento publicado em 6 de setembro de 1969, no Jornal do Brasil, intitulado "O artista perfeito", o qual retorna em 24 de março de 1973, sem outra modificação salvo a do título, "O ser livre". De novo, o artista e o ser clariceanos conjugados em perfeição e liberdade, idéia justamente bergsoniana e, dessa vez, ao filósofo creditada:

Num fragmento publicado em 6 de setembro de 1969, no Jornal do Brasil, intitulado "O artista perfeito", o qual retorna em 24 de março de 1973, sem outra modificação salvo a do título, "O ser livre". De novo, o artista e o ser clariceanos conjugados em perfeição e liberdade, idéia justamente bergsoniana e, dessa vez, ao filósofo creditada:

Não me lembro se é em Les donnés immediates de la conscience que Bergson fala do grande artista que seria aquele que tivesse, não só mais todos os sentidos libertos do utilitarismo (...) aquele que estivesse completamente livre de soluções convencionais e utilitárias veria o mundo, ou melhor, teria o mundo de um modo como jamais artista nenhum o teve. Quer dizer, totalmente e na sua verdadeira realidade (LISPECTOR: 1992ah, p. 242).

'Não me lembro se é em Les donnés immediates de la conscience' abre um precedente, anuncia parte da biblioteca invisível [10]. Precisamente, não se sabe se a citação parafraseada (provável tradução) é realmente a da obra referida, ou mesmo do autor. Sob a névoa, releva-se o argumento: a visão direta dada ao artista, potencializando um outro entendimento. Se ler é pensar, escrever é já entender:

Minhas intuições se tornam mais claras ao esforço de transpô-las em palavras. É neste sentido, pois, que escrever é uma necessidade. De um lado, porque escrever é um modo de não mentir o sentimento (a transfiguração involuntária da imaginação é apenas um modo de chegar); de outro lado, escrevo pela incapacidade de entender se não usar o processo de escrever. Escrever é compreender melhor (LISPECTOR: 1992ad, p. 452).

Escrevendo não se mente? Verdade imanente à inteligência que escreve, cuja maior faculdade é a de fabular, mentir:

Todas as mentiras são piedosas. A alegria de mentir é estética. De outro modo, só a verdade permite o prazer em si. 0 prazer estético é o maior, uma vez que, sob a forma da mentira, diz a verdade de uma maneira bastante geral (NIETSZCHE: 1987, p. 83).

Biológica garantia de uma sobre-vida: a verdade obedece razões ou necessidades de utilidade social, suas convenções são produção de disfarce - códigos lingüístico, moral. Verdade como adequação à realidade compartida pelo senso comum. No entanto, em "A perigosa aventura de escrever", em descompasso temporal, publicada em 05 de abril de 1969 (ou seja, muito anterior à reflexão acima, sinalizando 0 retorno de uma repetição), Clarice repensa o já dito:

Minhas intuições se tornam mais claras ao esforço de transpô-las em palavras'. Isso eu escrevi outra vez. Mas está errado, pois que, ao escrever, grudada e colada está a intuição (LISPECTOR: 1992ae, p. 191).

Re-conhecida como 'certeza', não mais dos sentidos, mas como um a priori, a crítica imediata procedente da intuição. Desse modo, na repetição, levando-se em consideração que não é a de um mesmo, se pode alcançar nova compreensão: se antes se experimentou no ato da escritura a profunda liberdade da criação, agora, a liberdade absoluta é pura coincidência, abandono das exigências impostas por uma vida gregária, prescindindo de juízos, conceitos, palavras. Mesmo que ainda seja através destas que a comunicação se faz, aquilo que está a "Máquina escrevendo":

Sinto que já cheguei quase à liberdade. A ponto de não precisar mais escrever. Se eu pudesse, deixava meu lugar nesta página em branco: cheio do maior silêncio. E cada um que olhasse se encheria com seus próprios desejos (LISPECTOR: 1992af, p. 375).

Campo aberto, de luz, de sombras, um sistema de visualidade análogo ao lingüístico: superfície, plano, fundo, luminosidade. Espaço não verbal. Parada na máquina de abordabilidade: nem fato, nem impressão, nem objeto nem sujeito. Desejo de pausa, do filósofo: "vou parar de escrever. Então começarei a pintar" (DELEUZE: 1996, 30), da escritora: "Se me fosse tirada a palavra pela qual tanto luto, eu teria que dançar ou pintar". (LISPECTOR: 1992ag, p. 94). Melville, autor de Bartleby, o escriturário, descreve a experiência diluidora de toda categorização. Catatonia dos sentidos. Anunciar o possível é preparar para uma realização, e realização supõe preferências, procede por exclusão, fins que variam, substituição dos precedentes, em suma, escolha. Mas decidir entre todas as variações, substituições, todas as 


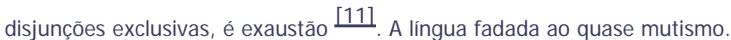

Maneira de entender, perceber aquilo que tende para uma direção ou para outra, a intuição como introspecção para fora:

Não era um não-entender como um simples de espírito. 0 bom era ter uma inteligência e não entender. Era uma bênção estranha como a de ter loucura sem ser doida (LISPECTOR: 1980, p. 53).

O acontecimento deixando o mundo das coisas para dar lugar a um tempo-espaço plenos, para depois, voltar ao mundo, às coisas, e deles ganhar uma visão, outra. João Cabral, também do círculo diplomático, convertido em amigo e interlocutor de Clarice, escreve a Manuel Bandeira a respeito da sensibilidade não habitual que exerceu aquela escritura; agora, no âmbito da literatura nacional:

(...) quando certo crítico de muitas campanillas (que é como se diz dos toureiros da moda) aconselhou Clarice Lispector que não publicasse seu primeiro livro, do qual, depois da aceitação dos não-habituados, acabou por escrever grandes elogios - se dava um caso de hábito de sensibilidade (...) (SÜSSEKIND: 2001, p. 68).

Movimento produtor de experiências do esvaziamento, desapropriando a forma anterior e dando limite à forma para sua dissolução, visando à expressão patética, a fim de conquistar a dimensão do orgiástico, do abissal. Não mais o grave e o pesado (realismo engajado, regional), mas a sutileza da superfície. Os acontecimentos ocorrendo no vazio, preenchendo-o de novidades, originais modos de sentir, de viver: a continuidade do avesso e do direito substituem a altura e a profundidade. Nada atrás da cortina, salvo misturas inomináveis. Nada acima do tapete, salvo o céu vazio (DELEUZE: 1994, p. 136). As 'crônicas' de Clarice, assim como o restante da escritura, são afirmação de um amor fati, posto que, genialmente, investem nas ficções, nunca realmente consumadas, jogo ficcional sempre aquém do fatalista, ou realista, da vida. Só assim parece salvar-se da loucura, dobrando-se nessa linha de morte, oceânica, onde a literatura acontece, como dirá Blanchot.

Portanto, aliada à riqueza das expressões ditas 'menores', encontradas na superfície da chamada 'baixa' produção, a crítica que tais textos imprimem é a de uma leitura do mundo, muitas vezes, contrária ao próprio universo que a localiza. Pois investe na liberdade da experiência, expressa pela matéria, aberta ao espírito. Sua contra-imagem, o crítico que, em palavras benjaminianas, "realiza a sua experiência, expressa pela materia, aberta ao espirito. Sua contra-imagem, o crítico que, em palavras benjaminianas, "realiza a sua
'experiência', sempre a mesma expressão da ausência de sensibilidade" (BENJAMIN: 1994, p. 25). Operação crítica, muitas vezes tentando fixar seu objeto, desvincula-o das possibilidades de movimento, de vôo. Taxonomista, técnico, educador. Noutra vertente, a autoridade deixa lugar

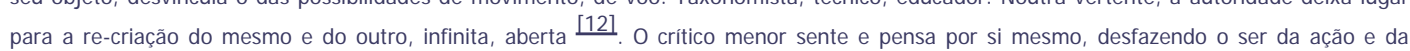
situação. Liberdade que se sobrepõe a esse mundo físico, de única lógica. Ligando ficções, ele habilita uma passagem do impossível para 0 possível, da identidade para a ex-tradição.

Experiência intermediada por nova percepção, sensibilidade inteligente que permite uma comunicação direta com o objeto [13] Comunicar da experiência que já é experiência. E se daí se pudesse compreender uma tarefa, seria mais conseqüente com uma produção de singularidades, sem planejamento, nem fins declarados possíveis $\underline{[14]}$ - do que propriamente a de agente cultural. Registro que afeta o leitor do jornal, possibilitando troca, desabafo, intercâmbio que não cabe no livro, quando exige aí um leitor de alma já formada $\frac{\text { [15] }}{0}$ monstro dando passagem ao bobo da corte, figura que (se) pensa e - com isso - a todos diverte. A dissolução dos discursos exigentes, combativos que conduzem, ou pretendem conduzir a um estado de alerta contínuo, de consciência crítica voltada para os grandes problemas humanos abre caminho para as experimentações fugazes, velozes, menos preocupadas com verdades e explicações do que com a eficácia imediata, com o resultado externo. Crítica, portanto, ao incrementar com práticas discursivas uma articulação entre política e vida.

Prática que se contrasta à da crítica dita maior, confinada aos espaços formais, mais propensa a explicações abstratas, negligenciando assim o factum vital que permeia toda a realidade (concreta): o processo absoluto. Citando Schiller, em carta de 1788, Clarice faz de suas palavras as dela, naquilo que coincide a respeito da arte e da crítica:

Vocês, dignos críticos, ou como quer que se denominem, têm vergonha ou temor da loucura momentânea e passageira que se encontra em todos os verdadeiros criadores e cuja maior ou menor duração distingue o artista pensador do sonhador. Daí provêm suas queixas de esterilidade, pois vocês rejeitam cedo demais e discriminam com excessiva severidade (LISPECTOR: 1992aj, p. 489).

Crítica mais próxima a que afirma Nietzsche, ao compreender que o conceito não pode avaliar a vida, ao contrário, deverá ele ser avaliado e interpretado pela vida. Não sendo possível atingir a vida pelas categorias do pensamento, restaria jogar o pensamento nas categorias da vida. E essas são precisamente as atitudes do corpo, suas posturas. A postura clariceana tergiversa, desfigura, esfacela, recompõe-se, conforme sensibilidade.

A observação do grande crítico clariceano recai sobre a cara combinação, sensibilidade e inteligência, como marcas mesmas da

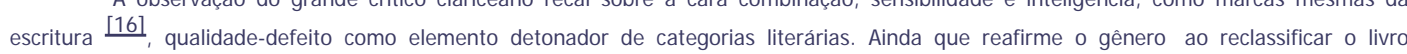
inaugural como 'romance autobiográfico'. Aliás, no qual a linguagem 'sensível' é concedida no exigido grau de subjetividade, por isso, da biografia, da poesia. Na página semanal no Caderno $B$ do Jornal do Brasil, exercendo a atividade de 'cronista', Clarice apresenta aí princípios que aborda uma primeira crítica de autobiografia, já que fala e pensa em primeira pessoa.

Justamente, ocupando esse lugar, Clarice Lispector confirma a assinatura de SI (sensibilidade inteligente): "eu uso quando escrevo, e nas minhas relações com amigos, é esse tipo de sensibilidade" (LISPECTOR: 1992ab, p. 152). Si como sinônimo de literatura, mas também de afeto. Colocação que no aberto do jornal pode sugerir crise, ao indagar como se apresentar nesse espaço - qual si mesma? Explicitado sempre que essa narrativa, de si, nada tem a ver com história pessoal: "Muita coisa não posso te contar. Não vou ser autobiográfica. Quero ser 'bio' (LISPECTOR: 1973, p. 40). Por conseguinte, autobiografia, tipo de escritura que transcende a propriedade da vida, é "a vida vista pela vida" (LISPECTOR: 1973, p. 19)

\section{Referências:}

BENJ AMIN, Walter. "Experiência". Reflexões: a criança, o brinquedo, a educação. Trad. Marcus Vinicius Mazzari. São Paulos: Summus, 1994. . "Experience". Selected writings. Vol. 2, 1927-1934. Cambridge, Massachusetts, London: Harvard University Press, 1999.

BERGSON, Henri. O Riso - ensaio sobre o significado do cômico. Trad. Guilherme de Castilho. Lisboa: Guimarães Edit, 1993.

A I ntuição filosófica. Trad. Maria Neves. Lisboa: Colibri, 1994.

Catálogo da XXIV Bienal de São Paulo - Núcleo histórico - antropofagia e histórias de canibalismo. Org. Kátia Canton. São Paulo: A Fundação, 1998.

Correspondência de Cabral com Bandeira e Drummond. Org. e apres. Flora Süssekind. Rio de Janeiro: Nova Fronteira, Fundação Casa de Rui Barbosa, 2001.

DELEUZE, Gilles. "L' epuisé". In: BECKETT, Samuel. Quad et autres pièces pour la télévision. Paris: Les Éditions de Minuit, 1992. "Meu próximo livro vai chamar-se Grandeza de Marx". In: Cadernos de subjetividade, número especial. Coord. Suely Rolnik. São

Paulo: PUC, 1996

DELEUZE, Gilles. Lógica do Sentido. Trad. L.S. Fortes. São Paulo: Perspectiva, 1994.

DELEUZE, Gilles. GUATTARI, Felix. O que é filosofia? Trad. Bento Prado J r e Alberto Alonso Muñoz. Rio de Janeiro: Editora 34, 1993.

DRUMmOND de ANDRADE, M. J. "Carlos Drummond de Andrade fala a Maria Julieta Drummond de Andrade". O Globo. Rio de Janeiro, 29 de janeiro de 1984

FRANCIS, P. "Clarice: impressões de uma mulher que lutou sozinha". São Paulo: Folha de São Paulo, 15 e dezembro de 1977.

HENFIL. "Clarice, Luana, só a Índio do Brasil, com dois ss". Rio de Janeiro: O J ornal, 20 de julho de 1973.

LAMARE, Germana de. "Clarisse Lispector esconde um objeto gritante". Rio de Janeiro: Correio da Manhã, 6 de março de 1972.

LISPECTOR, Clarice. "Das vantagens de ser bobo". A Descoberta do Mundo. Rio de Janeiro: Francisco Alves, 1992aa.

"Sensibilidade inteligente". A Descoberta do Mundo. Rio de Janeiro: Francisco Alves, 1992ab.

"As três experiências". A Descoberta do Mundo. Rio de Janeiro: Francisco Alves, 1992ac.

"Sem aviso". A Descoberta do Mundo. Rio de J aneiro: Francisco Alves, 1992ad.

"A perigosa aventura de escrever". A Descoberta do Mundo. Rio de Janeiro: Francisco Alves, 1992ae.

"Máquina escrevendo". A Descoberta do Mundo. Rio de Janeiro: Francisco Alves, 1992af.

"Adeus, vou-me embora". A Descoberta do Mundo. Rio de Janeiro: Francisco Alves, 1992ag. 
"O artista perfeito". A Descoberta do Mundo. Rio de Janeiro: Francisco Alves, 1992ah.

"Autocrítica no entanto benévola". A Descoberta do Mundo. Rio de Janeiro: Francisco Alves, 1992ai.

"Carências do poder criador". A Descoberta do Mundo. Rio de Janeiro: Francisco Alves, 1992aj..

De corpo inteiro. São Paulo: Siciliano, 1992b.

Água viva. São Paulo: Círculo do livro, 1973.

Uma aprendizagem ou o livro dos prazeres. Rio de Janeiro: Francisco Alves, 1980.

MARTINS, Maria. Deuses Malditos: I. Nietzsche. Rio de Janeiro: Civilização Brasileira, 1965.

MILLIET, Sérgio. O Diário crítico de Sérgio Milliet, vol. VII. $2^{\text {a }}$ ed. São Paulo: Martins Editora-EDUSP, 1982.

NIETZSCHE, Friederich. "Libertad de la voluntad y fatum" (Pforta, abril de 1862). De mi vida. Escritos autobiográficos de juventud (1856

1869). Trad. Luis Fernando Moreno Claros. Madrid: Valdemar, 1997.

O Livro do Filósofo. Trad. Rubens Eduardo Ferreira Frias. São Paulo: Editora Moraes, 1987.

SARTRE, J ean-Paul. O ser e o nada. Trad. Paulo Perdigão. Petrópolis: Vozes, 1997.

Textos Cautivos - Ensayos y reseñas en ‘El Hogar' (1936-39). Edición de Enrique Sacerio-Garí y Emir Rodríguez Monegal. Barcelona: Tusques Editores, 1986.

TREVISAN, Armindo. Le Probleme de la creation chez Bergson (fotocópia). Suíça: 1963.

Recebido em 17/ 04/ 2008. Aprovado em 03/ 06/ 2008.

Title: The Kidnapping of Symbolism in the Magazine J oaquim: the Cry of the Vampire Against the Sighing of the Nefelibat

Author: Caio Ricardo Bona Moreira

Abstract: In this essay I propose a counter-modernist reading of the radical stand by the magazine Joaquim contra 0 Simbolismo Paranaense (J oaquim Against the Symbolism of Paraná State). The magazine, created in 1946 by the writer from Curitiba, Dalton Trevisan, was published till 1948, a period of ascent of Existentialism in the postwar literary scene in the Brazilian state of Paraná. The monthly magazine refuses Symbolism, since it was considered by Dalton Trevisan as a literature, which was not tuned with his production and with man's and the world's problems. I intend to note that the issue of its genesis treated as origin by the magazine does not hold as a tool for critical practices.

Keywords: magazine Joaquim, Modernism, Symbolism in Paraná

Tìtre: La séquestration du Symbolisme dans la Revue Joaquim: Le Cri du Vampire contre le susurrement du Nefelibata Auteur: Caio Ricardo Bona Moreira

Résumé: Je propose dans cet article une lecture contre-moderniste à propos de la position radicale de la revue Joaquim contre le Symbolisme Paranaense. La revue, fondée en 1848, période de l'ascension de l'existentialisme dans le scénario littéraire du post-guerre. II se dégage de sa position autonomiste le souhait de faire débuter officiellement la littérature du Paraná. Le périodique refuse le symbolisme, puisque Dalton l'a considéré comme une littérature qui n'a pas syntonisé sa production avec les problèmes de l'homme et du monde. J'ai l'intention d'observer que la question de la genèse traitée comme origine par la revue ne se soutient pas comme fondement pour les pratiques critiques.

Mots-clés: Revue J oaquim, Modernisme, Symbolisme du Paraná

Título: El Secuestro del Simbolismo e la Revista Joaquim: el Grito del Vampiro Contra el Susurro del Nefelibata

Autor: Caio Ricardo Bona Moreira

Resumen: Propongo en este artículo una lectura contra-modernista de la posición radical de la revista Joaquim contra e Simbolismo Paranaense. La revista, fundada en 1946, por el escritor de Curitiba Dalton Trevisan, circuló hasta 1948, período de ascensión del existencialismo en el escenario literario de posguerra. Se desprende de su posición autonomista el deseo de iniciar oficialmente la literatura en Paraná. El periódico recusa el simbolismo, pues fue considerado por Dalton como una literatura que no sintonizó su producción con los problemas del hombre y del mundo. Pretendo observar que la cuestión del génesis tratado como origen por la revista no se sustenta como fundamento para prácticas críticas.

Palabras-clave: Revista J oaquim, Modernismo, Simbolismo Paranaense.

Notas:

*Profa. Dra. em Teoria Literária (UFSC), professora de Literatura e Teoria da Comunicação (sicuri@ig.com.br).

[1] BERGSON, H. O riso - ensaio sobre o significado do cômico, 1993, p. 112.

[2] LISPECTOR, C. "Autocrítica no entanto benévola". A Descoberta do Mundo, 1992, p. 212

[3] Maria Martins, escritora, jornalista e artista plástica, nasceu em Campanha, Minas, em 1900, e morreu no Rio em 1973. Em 1941, faz sua primeira exposição individual, em Nova York. Ela é a musa de Marcel Duchamp, seu corpo serve de modelo para Étant Donnés. Exposta em sua intimidade aos olhos do público voyeur, no entanto, é lhe cortada qualquer possibilidade de identificação, o rosto está coberto por espessa cabeleira. Musa sem rosto, como as inquietantes de De Chirico. A curadora de Maria em São Paulo, Kátia Canton, nomeia-a de Nossa Senhora dos desejos. Cf. o catálogo da XXIV Bienal de São Paulo - Núcleo histórico - antropofagia e histórias de canibalismo, 1998.

[4] Nietzsche em "Libertad de la voluntad y fatum", 1997, faz a distinção entre os termos fatum e factum. Enquanto o fato, o fatum, diz respeito ao ordinário da vida, é somente um conceito abstrato, uma força sem matéria. E que para o indivíduo apenas há um fatum individual, uma concatenação de acontecimentos, que se determina seu próprio fatum enquanto atua, mas - lembra o filósofo - a atividade do homem não começa com o nascimento, senão muito antes. Conclui, os hindus dizem que o fatum não é outra coisa que os fatos que levados a cabo numa condição anterior de nosso ser. Já o factum estaria para o pensamento, o extraordinário, em uma palavra, a ficção.

[5] Já Henfil, ao responder à sugestão de uma leitora para que o Pasquim entrevistasse Clarice Lispector, refuta: "Clarice, Luana, só a Índio do Brasil, com dois ss". Em depoimento a O Jornal, em 1973, Henfil explicita o severíssimo castigo imposto à escritora e suas razões: "Eu a coloquei no Cemitério dos Mortos-Vivos porque ela se coloca dentro de uma redoma de Pequeno Príncipe, para ficar num mundo de flores e de passarinhos, enquanto Cristo está sendo pregado na cruz. Num momento como o de hoje, só tenho uma palavra a dizer de uma pessoa que continua falando de flores: é alienada. Não quero com isso tomar uma atitude fascista de dizer que ela não pode escrever o que quiser, exercer a arte pela arte. Mas apenas me reservo o direito de criticar uma pessoa que, com o recurso que tem, a sensibilidade enorme que tem, se coloca dentro de uma redoma. (...) Ela escreve bem à beça, um potencial excelente para entender as angústias do mundo. 0 maior respeito todo mundo tem por Clarice Lispector. No entanto, ela não toma conhecimento das causas e dos motivos desses problemas existenciais, não só dela como do mundo inteiro. Foi por isso que botei a Clarice lá. Ela não gostou, e eu não vou tomar uma atitude fascista de matá-la".

Clarice, por sua vez, replica, "sou ignorante demais para ser uma intelectual. Não sou uma literata. Não vivo no meio dos livros, nem tampouco de flores e de aves, como me acusam às vezes... Sou uma intuitiva, quer dizer, eu sinto mais que penso". "Clarisse Lispector esconde um objeto gritante". Entrevista por Germana de Lamare para o Correio da Manhã.

[6] Clarice é substituída, nesse espaço que ocupou de 1967 até 1973 , no Jornal do Brasil, por outro monstro, de ferro, Carlos Drummond. É o poeta quem define crônica, sua função e por conseqüência, a do cronista: "É um gênero menor e engraçado, que se enquadra exclusivamente no segundo caderno dos jornais. Esse tem, a meu ver, a função de corrigir o primeiro, que é um estoque fabuloso de terremotos, crimes e misérias. Depois de tomar contato com tudo isso, durante o café da manhã, o leitor precisa de distração. Como cronista, eu me sinto um palhaço, um 'jongleur', dando saltos e cabriolas, fazendo molecagens". "Carlos Drummond de Andrade fala a Maria Julieta Drummond de Andrade". O Globo, 1984, p. 3.

[7] 0 idiota é personagem conceitual ("heterônimo do filósofo"), ele se opõe ao professor público, uma vez que este opera com "conceitos ensinados", enquanto o primeiro forma um conceito com "forças inatas que cada um possui de direito por sua conta (eu penso)". Cf. DELEUZE, G. GUATTARI, F. O que é filosofia? 1993, p. 83.

[8] No que diz respeito à artista, em específico, a liberdade atrelou-se ao seu movimento. Recorto do catálogo da XXIV Bienal de São Paulo 
- Núcleo histórico - antropofagia e histórias de canibalismo, a seguinte observação: "De fato, a liberdade com que mergulha e emerge de universos estéticos e culturais diversos, constantemente carimbados com uma marca narrativa extremamente pessoal, intuitiva e emocional, faz com que Maria Martins seja desde o início identificada ao surrealismo". "Maria Martins: a mulher perdeu sua sombra". Curadoria Katia Canton, p. 289

[9] MARTINS, M. Deuses Malditos: I. Nietzsche, 1965.

[10] Bergson, em tese de doutoramento, discute a noção de intuição, categoria de conhecimento que nesta leitura reenvia à escritura de Clarice: Essai sur les donnés immédiates de la conscience. Justamente é sobre a criação a tese de Armindo TREVISAN, Le Problème de la création chez Bergson, defendida na Suiça, em 1963, e dedicada, em 1964, à Clarice. Texto encontrado na biblioteca particular da escritora doada à Fundação Casa de Rui Barbosa.

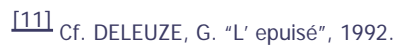

[12] Remissão ao filisteu de Benjamin que equivale ao professor de Clarice. Sobre esse personagem conceitual cf. meu estudo anterior A escritura nômade em Clarice Lispector, 2001. Diz BENJ AMIN: à criança é proposta outra experiência, na qual "vivenciará o espírito, e quanto mais difícil lhe seja conquistar algo grandioso, mais facilmente encontrará o espírito em sua caminhada e em todos os homens. 0 jovem será amável como homem adulto. O filisteu é intolerante", W. "Experiência", p. 25. Amabilidade, amizade, atributo grego, generoso compartilhar de potência, e isso que se dá é tão abundante que não se pode evitar. É mesmo dom. De outra forma, seria contenção, lógica do saber contido à moral do professor (leia da minha cartilha!)

[13] Cf. BENJ AMIN, W. “Experience", 1999.

[14] Contrapondo-se a um programa, por exemplo, borgeano. Entre 1936 a 1939, colaborador crítico e também diretor da seção 'Libros y autores extranjeros', Borges publica resenhas sobre os mais variados gêneros: aventura, ficção científica, policial, fantástico, para a revista 'El Hogar'. Em detida leitura, nas resenhas policiais, percebe-se a elaboração - e execução - de um plano que implica uma teoria do ser leitor, e por conseguinte, do conhecimento. Não se pode negligenciar o caráter pedagógico que reveste 'El Hogar'. Fundada em Buenos Aires, em 1904, tendo como propósito primeiro reproduzir os fatos (ilustrados) importantes ocorridos no país e no mundo, durante a semana; além de seções dirigidas às donas de casa sobre economia doméstica, cozinha, educação, higiene, beleza; até informativos de cunho político, esportivo, tecnológico, artigos de valor literário, assinados por autores de renome como Martínez Estrada, Arlt. Se por um lado, sabemos a recusa do autor argentino por qualquer projeto pedagógico, por outro, é sintomática a colaboração neste tipo de imprensa, que define a si mesma, em 1914, como: "( rechazará todo desvio de tendencia equivoca y dudosa. (...)", (apontamentos, citação e informações pelo prólogo da antologia, por Enrique Sacerio-Garí). Textos Cautivos - Ensayos y reseñas en 'El Hogar' (1936-39), 1986.

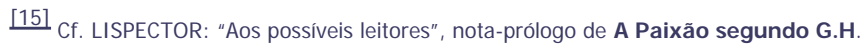

[16] Em 27 de agosto de 1949, o crítico Milliet, que havia consagrado o primeiro texto da escritora, identifica o segundo, A Cidade Sitiada, a um 'temperamento feito de curiosidade sensual e sensibilidade angustiada', cuja 'inteligência não analisa, não observa, apenas exprime, em imagens inesperadas e sutis, aquilo que os sentidos apreendem'. Para ele, características que descrevem o gênero poema em prosa mais do que romance, diz "Enquanto o romance permaneceu nos domínios mais ou menos velados da autobiografia, tais qualidades e defeitos não 0 prejudicaram". O Diário crítico de Sérgio Milliet, 1982, p. 34.

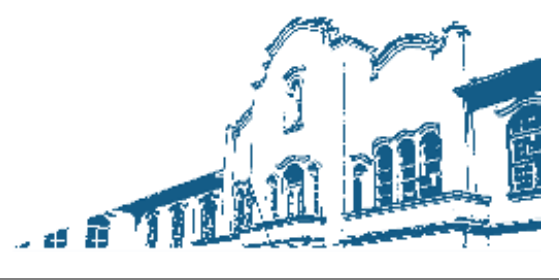

Copyright PPGCL/ Unisul 2006 @ (48) 3621-3369 - Desenvolvimento: Prof. Dr. Fábio J osé Rauen 